\title{
"Gastritis" of nodular bulb-duodenal mucosa?
}

\section{Daniel Țuculanu*, Dorina-Monica Pârva and Andrei Ţuculanu}

Department of Gastroenterology of Ţuculanu Medical Center, Timișoara, România

\section{Introduction}

Seldom, the endoscopic examination of the duodenum reveals the nodular appearance of the mucosa on a variable surface area.

Duodenal nodules are often benign and have a substrate Brunner hypertrophic gland, metaplasia or heterotipia of gastric mucosal, as well as hyperplasia of duodenal structures/lymphoid nodules.

We present the case of a patient with bulb mucosa with nodular appearance, identified by upper digestive endoscopy and by virtual chromoendoscopy type FICE (Fujinon Intelligent Color Enhancement).

\section{Case}

A 43-year-old patient with a history of duodenal ulcer and gastroesophageal reflux disease addressed our service with abdominal pain in the epigastrum and the right hypochondrium. Abdominal ultrasound has not found changes in the gallbladder, biliary tree and pancreas.

Instead, esophago-gastro-duodenoscopy revealed a mosaic aspect of the antral mucosa (Figure 1) as well as nodular areas in the duodenal bulb (Figures 2-4), more easily visualized by FICE chromoendoscopy Fujinon Intelligent Color Enhancement.
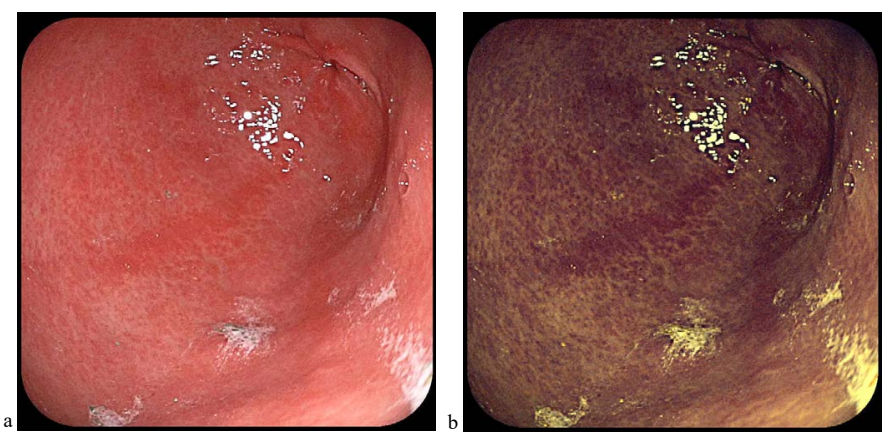

Figure 1. Antral gastritis (a-classical videoendoscopy, b-FICE chromoendoscopy)
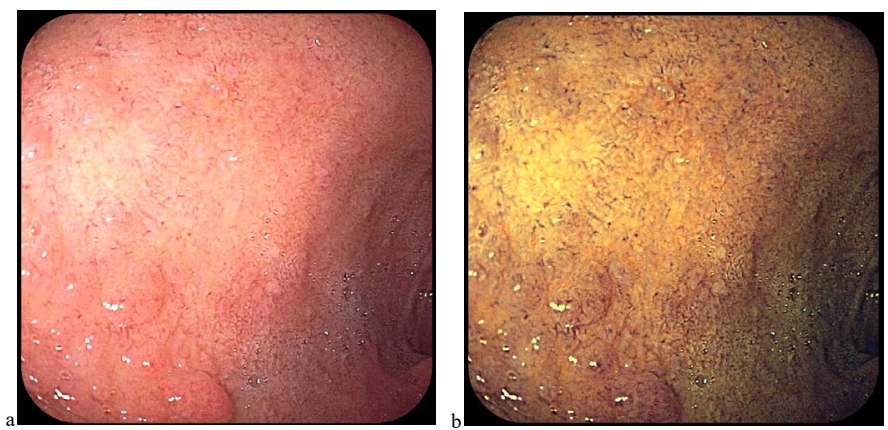

Figure 2. Duodenal nodules more easily detected in the FICE examination than in white light (a-classic videoendoscopy, b-FICE chromoendoscopy)
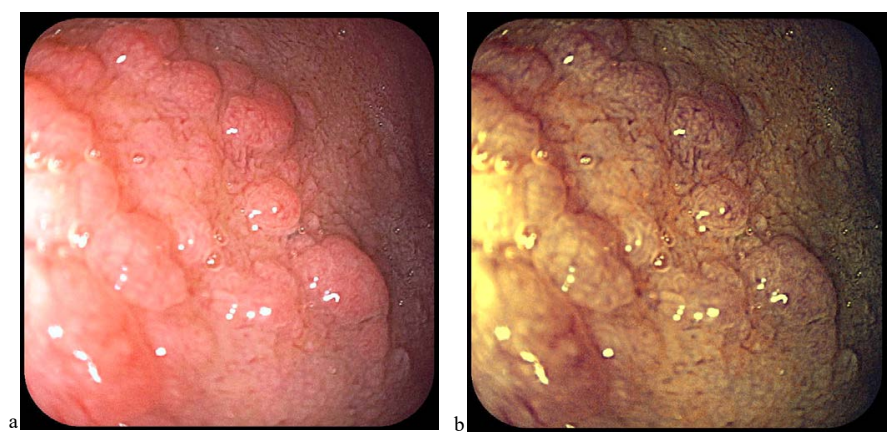

Figure 3. Nodular duodenal mucosa corresponding to a bulbar island of gastric heterotophia (a-classical videoendoscopy, b-FICE chromoendoscopy)
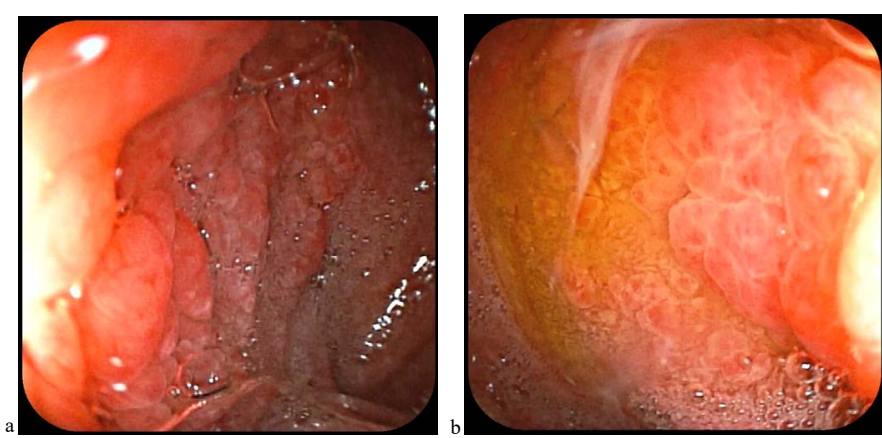

Figure 4. Heterotopic gastric mucosa at the duodenum level similar to folds (a) and gastric areas (b) of the gastric body

Histopathological nodules were formed from fundic gastric epithelium (Figure 5), containing main and parietal cells (Figure 6). In some places was evidenced inflammatory lymphoplasmacytic infiltrate, but not Helicobacter pylori colonies (Figure 7).

Following patient on a two-year interval, we found relatively favorable antisecretory effect on symptoms, but persist the endoscopic and microscopic appearance (Figure 8).

\section{Discussion}

Heterotopic gastric mucosa (HGM) can be identified anywhere in the digestive tract [1]: tongue [2], esophagus [3], duodenum [4,5], jejunum [6], ileum [7], Meckel diverticulum [8], colon, rectum $[9,10]$, anus [11] and gallbladder [12]. In duodenum was first reported at necropsy (Taylor in 1927). Endoscopic described in 1970, is considered

${ }^{*}$ Correspondence to: Daniel Țuculanu, Department of Gastroenterology of Ţuculanu Medical Center, Timișoara, România, Tel. 0040.728.955.432; E-mail: danieltuculanu@yahoo.com

Received: June 05, 2018; Accepted: June 14, 2018; Published: June 16, 2018 


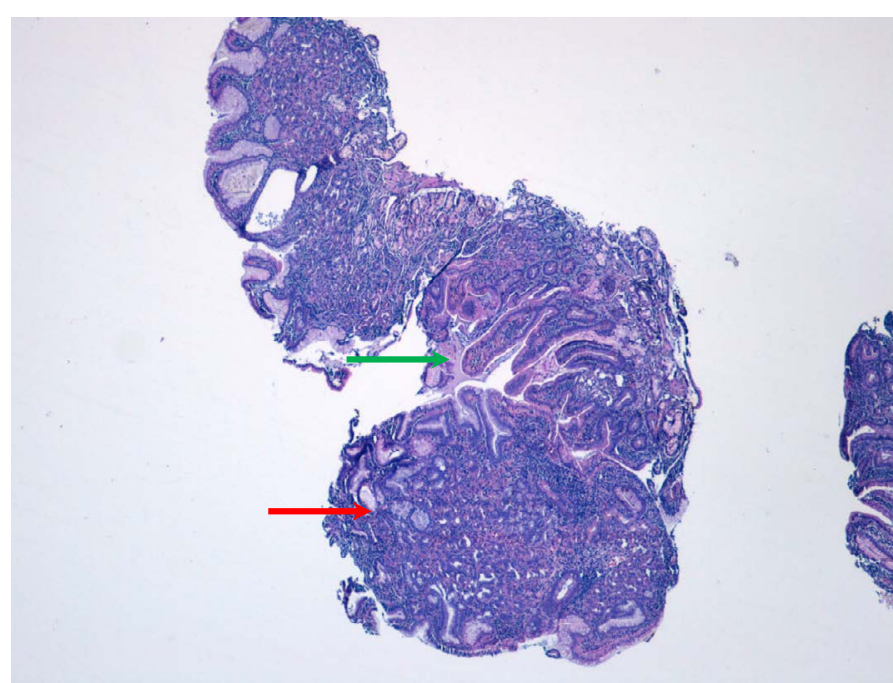

Figure 5. Nodular formation consisting of ectopic mucosa at gastric mucosa (red arrow) Normal duodenal mucosa (green arrow)

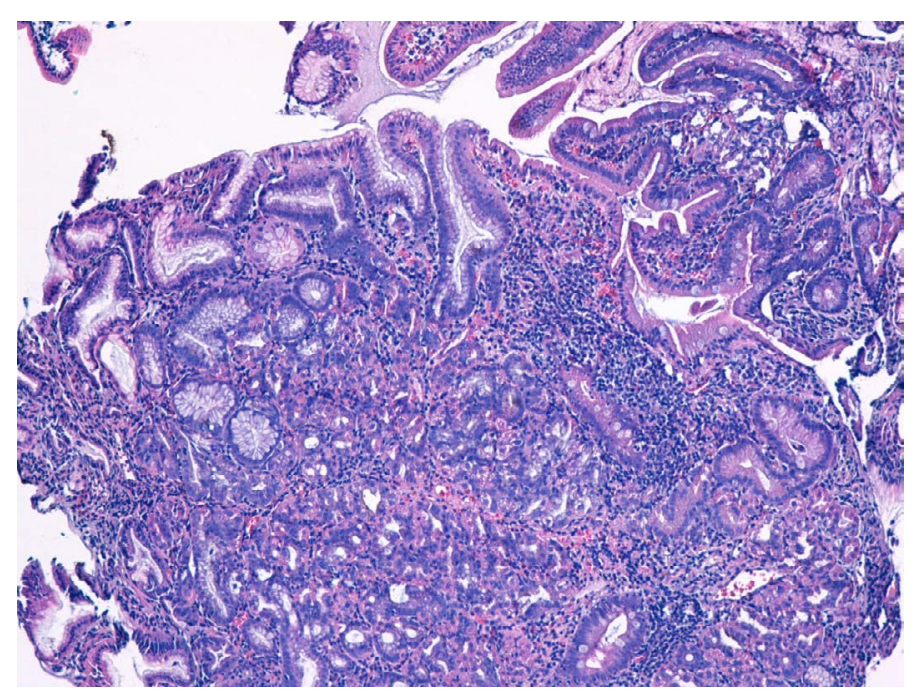

Figure 6. Duodenum mucosal and submucosal fragments with partially preserved architecture and with presence of proeminent nodular formations made up of gastric body mucosa, with superficial glands and crowded glands. Rare glands cystic dilated. HP negative

a rare occurrence $(0,5-2 \%$ of the population) [13] so that the first endoscopic identification until now $30-80$ cases were reported.

Gastric epithelium areas appear macroscopically/endoscopically in the form of isolated duodenal nodules, certain nodular mucosa or duodenal mucosa with discreetly modified architecture. Introduction of classical chromoendoscopy (intravital colaration) or virtual chromoendoscopy (NBI, FICE, i-Scan) allows for better evidence of relief of digestive mucosa (Figure 9), including heterotophic gastric mucosa (e.g., at the esophagus or duodenum level, in our case). The images presented in this material, captured using FICE technology, are among the few in the FICE spectral light.

The real HGM is congenital and must be distinguished from gastric metaplasia in the duodenum at antral type or pyloric type which are methods of duodenal mucosal response and protection from clorhidropeptic aggression, often associated with ulcer or inflammatory duodenal lesions. On the contrary, the real HGM, in most cases, seems to prevent ulceration and inflammation of the surrounding normal duodenal mucosa, through mechanisms insufficient specified but highlighted statistically.

Heterotopic mucosal islands may, however, become inflamed (Figure 10) following chemical aggression (chlorhydro-peptic, biliary, medicamentary) or colonization with Helicobacter pyloriHP (in our case HP has not been identified). Other complications of the heterotophic gastric mucosa may be ulceration, (Figure 11),
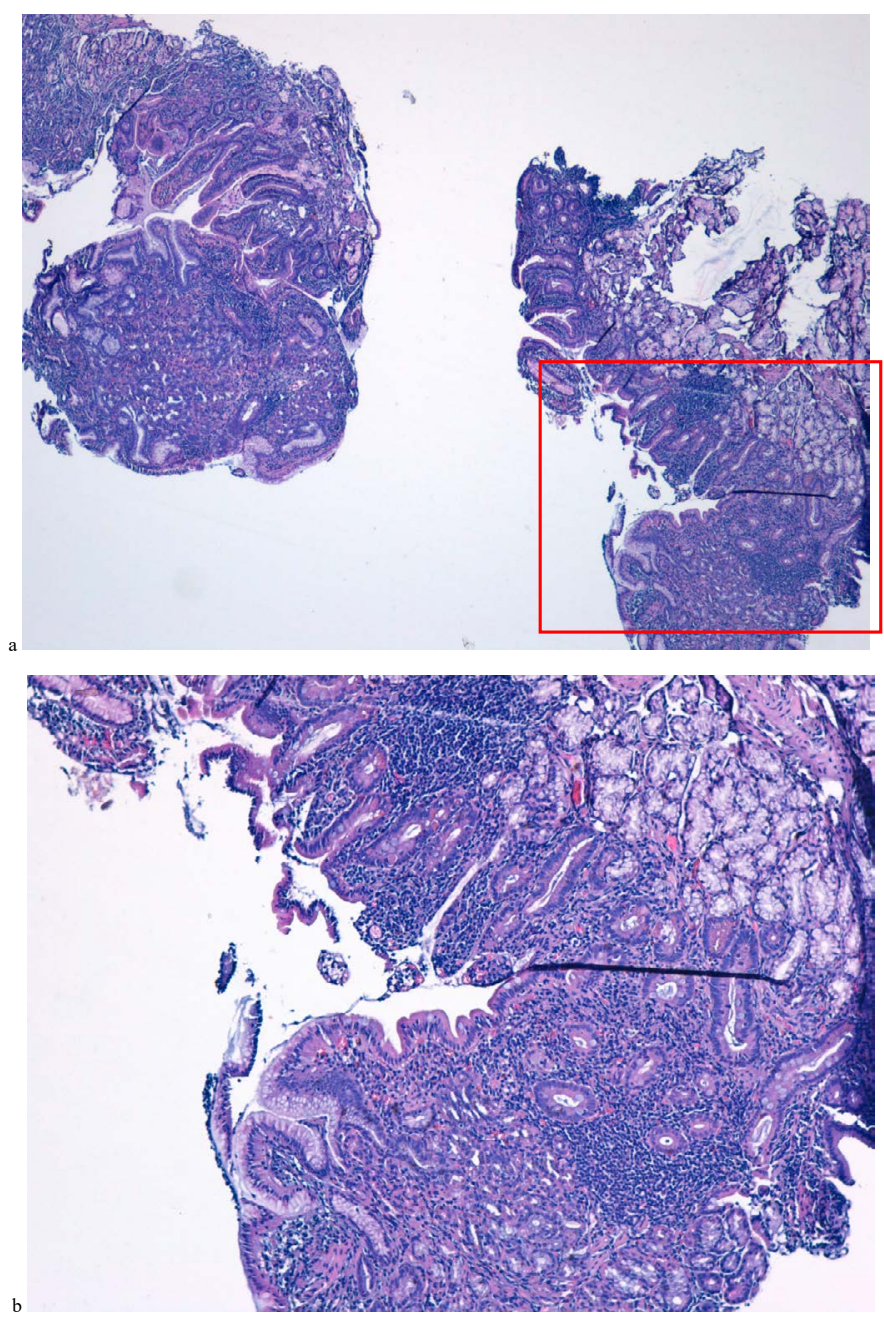

Figure 7. Corion with inflamed lympho-plasmocytar and eosinocytar infiltrate (a and b)

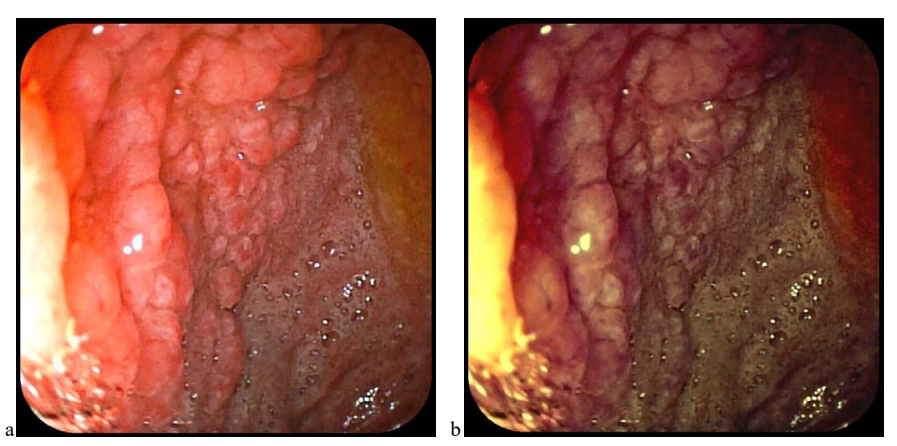

Figure 8. The same aspect of the nodular mucosa a few months after the previous examination (a-classic videoendoscopy, b-FICE chromoendoscopy) 
hemorrhage, duodenal stenosis, perforation and (at least theoretically) malignant transformation (adenocarcinoma or carcinoid depending on the affected cell line), in the heterotophic areas being identified principale, parietal and enterocromafine cells (Figure 12).
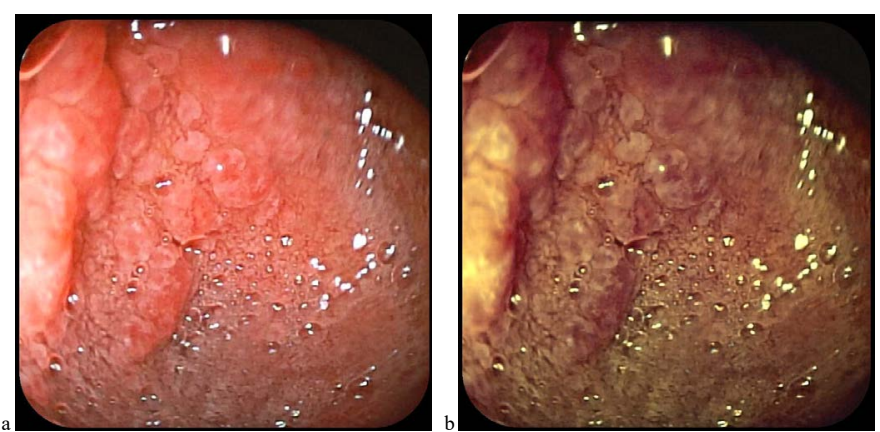

Figure 9. Mucosa with nodular architecture better visible by examination in colored light (FICE)

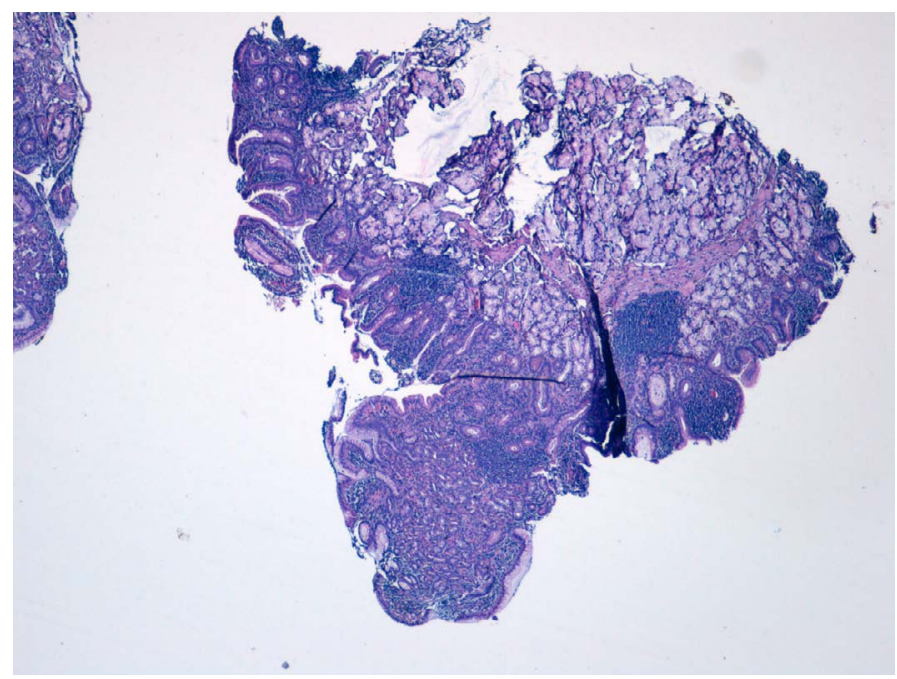

Figure 10. Small nodular aggregates of lymphocytes in corion

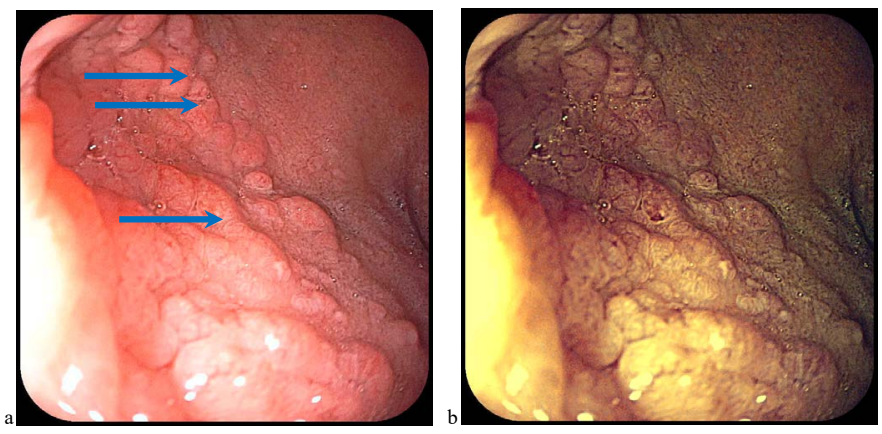

Figure 11. Small ulcerations (blue arrow) on the nodule surface (a-classical videoendoscopy, b-FICE chromoendoscopy)

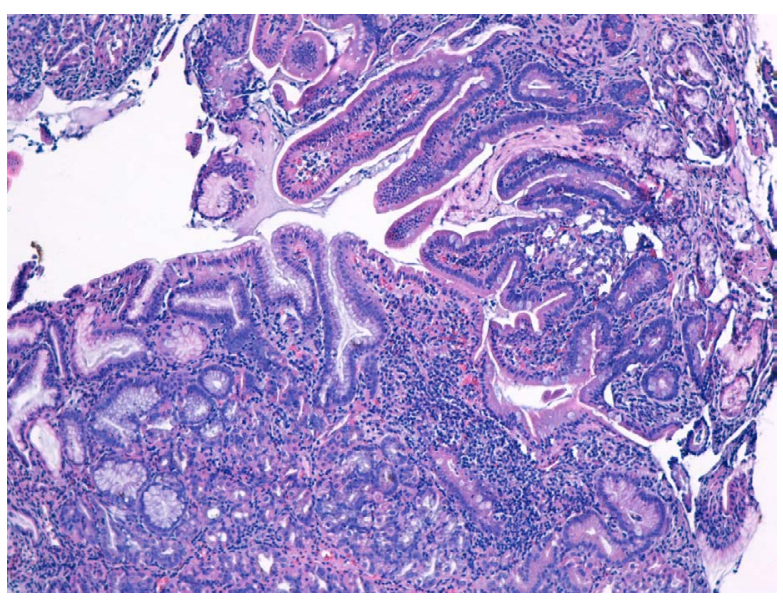

Figure 12. Gastric body mucosa in the duodenum, with superficial glands gathered with cylindrical muco-secretory epithelium and crowded glands bounded by specialized cells in depth. Rare glands cystic dilated

\section{Disclosure}

No conflicts of interest. No grants or financial support.

\section{References}

1. Terada $\mathrm{T}$ (2007) Heterotopic gastric mucosa of the gastrointestinal tract: a histopathologic study of 158 cases. Pathol Res Pract 3: 148-150. [Crossref]

2. Ortiz MJ, Fay JT, Weir GT (1982) Heterotopic gastric mucosa of the tongue. J Oral Maxillofac Surg 40: 667-670. [Crossref]

3. Neumann H, Schmidt H (2013) Advanced endoscopic imaging for characterization of heterotopic gastric mucosa in the esophagus. Elsevier $\mathrm{GmbH}$.

4. Terada T (2012) Pathologic observations of the duodenum in 615 consecutive duodenal specimens: I. benign lesions. Int J Clin Exp Pathol 5: 46-51. [Crossref]

5. Shousha, S, Spiller RC, Parkins RA (1983) The endoscopically abnormal duodenum in patients with dyspepsia: biopsy findings in 60 cases. Histopathology 7: 23-34.

6. Jimenez JC, Emil S, Steinmetz B, Romansky S, Weller M (2005) Recurren gastrointestinal tract bleeding secondary to jejunal gastric heterotopia. J Pediatr Surg 40: 1654-1657. [Crossref]

7. Turck D, Bonnevalle M, Gottrand F, Farriaux JP (1990) Intraoperative endoscopic diagnosis of heterotopic gastric mucosa in the ileum causing recurrent acute intussusception. J Pediatr Gastroenterol Nutr 11: 275-278. [Crossref]

8. Sfak-ianakis GN, Conway JJ (1981) Detection of ectopic gastric mucosa in Meckel's diverticulum and in other aberrations by scintigraphy: I. Pathophysiology and 10-year clinical experience. J Nucl Med 22: 647-654.

9. Iacopini F, Gotoda T, Elisei W, Rigato P, Montagnese F, et al. (2016) Heterotopic gastric mucosa in the anus and rectum: first case report of endoscopic submucosal dissection and systematic review. Gastroenterol Rep (Oxf) 4: 196-205. [Crossref]

10. Colsa-Gutiérrez P, Kharazmi-Taghavi M, Sosa-Medina RD, Berrío-Obregón JI, Ingelmo-Setién A (2016) Heterotopic gastric mucosa in the rectum: Report of a case. Cir Cir 84: 160-163. [Crossref]

11. Steele SR, Mullenix PS, Martin MJ, Ormseth E, Weppler E, et al. (2004) Heterotopic gastric mucosa of the anus: a case report and review of the literature. Am Surg 70 715-719. [Crossref]

12. Yasuhiro SH, Motoo S, Kazuaki T, Miri H, Satoshi F, Katoh KH (2010) Heterotopic gastric mucosa in the gallbladder: Report of two cases. Surgery Today 40: 783-787. [Crossref]

13. Mann NS, Mann SK, Rachut E (2000) Heterotopic gastric tissue in the duodenal bulb. J Clin Gastroenterol 30: 303-306. [Crossref]

Copyright: $\odot 2018$ Țuculanu D. This is an open-access article distributed under the terms of the Creative Commons Attribution License, which permits unrestricted use, distribution, and reproduction in any medium, provided the original author and source are credited. 